\title{
Environmental Factors Related to Acute Rheumatic Fever and Rheumatic Heart Disease in Aceh Province
}

\author{
Herlina Dimiati ${ }^{1}$, Sofia Sofia ${ }^{1}$, Gani $\mathbf{B}^{2}$ \\ ${ }^{1}$ Faculty of Medicine, Universitas Syiah Kuala, Zainoel Abidin Hospital, Banda Aceh, Indonesia \\ ${ }^{2}$ Oral Biology Department, Faculty of Dentistry, Universitas Syiah Kuala, Banda Aceh, Indonesia \\ herlinadimiati@unsyiah.ac.id
}

\begin{abstract}
Acute rheumatic fever (ARF) is the body's immune system reacting to an untreated infection with Group A Streptococcus (GAS) that affects skin, joints, brain, and heart. The heart damage that remains after an occurrence of ARF is called rheumatic heart disease (RHD). The objective of this study was to evaluate the ARF and RHD based on the profile of clinical diagnoses and emerging factors. The data were collected through interviews of the subjects, complete blood counts, the anti-streptolysin titer $O$ analysis, the $C$-reactive protein Assay, and a statistical analysis. This research was a combination of clinical assessments, the CRP kit, anti-titer $O$ kit, and interviews. The data were analyzed by employing Wilcoxon, Chisquare and Friedman test and also included a correlation analyzed using Spearman's correlation with significance of $(p<0.05$. There were 63 samples of ARF and RHD patients involved, consisting of male (50.8\%:32) and female (49.9\%:31) patients ( $p<0.05)$. The factors that triggered ARF and RHD $(p<0.05 ; r=0.88)$ as well as laboratory diagnosis $(p<0.05)$ of these infections were measured. The ARF caused by residence also caused RHD by the interaction of time with the environment $(p<0.05)$. The population consisted of males $(32: 50.8 \%)$ and females (31:49.2\%), and it was not significant ( $p>0.05)$, while the streptococcal infection of RHD (63.5\%) was much larger than in ARF (36.5\%). This was based on the clinical diagnosis of RHD and ARF with a significance of ( $p<0.05)$. Also, the residence and the period of interaction with the environment were influences on the RHD and ARF.
\end{abstract}

Keywords: streptococcal infection; acute rheumatic fever; rheumatic heart disease; environmental factors

\section{Introduction}

Acute rheumatic fever (ARF) due to the autoimmune response to esophageal infections was caused by the Streptococcus pyogenes (group A Streptococcus), with clinical manifestations such as inflammation of the joints (arthritis) and heart (carditis), acute migrainous polyarthritis, chorea, subcutaneous nodules, and erythema marginatum (Hu W, 2018). These infections affect children aged 5-15 years who can be classified with connective tissue disease or collagen vascular disease due to the particular injury of collagen fibrils and substances of the composition of connective tissues (Rothenbühler, 2014).

Acute manifestations of ARF were shown after a GAS infection (group A streptococcus) in the tonsil-pharynx. There is a latent period of about 3 weeks which can cause cardiac valve fibrosis, resulting in hemodynamic disturbances in the Rheumatic Heart Disease (RHD) infection.(Watkins, 2017). GAS is a family of species that causes infections throughout the body, such as induction of the throat (strep throat) and impetigo (skin sores) (Oliver, 2017) which can be life- threatening. Prevention of widespread infections is usually achieved by giving Long-acting bacillin (LAB), which is a penicillin antibiotic injected into a muscle, to protect against infection for 28 days (Oliver, 2017). The development of ARF occurs approximately two weeks after the $\mathrm{S}$. pyogenes infection with symptoms and clinical manifestations assessed using the Jones criteria. Meanwhile, RHD is the effect of prolonged cardiac damage triggered by complications of the ARF infection. RHD is reported to have a negative impact on child morbidity and mortality in the world (Carapetis, 2016). 
Worldwide, ARF is a major cause of acquired heart disease in 5-30 million children and young adults, of which 90.000 die each year, and worldwide mortality ranges between 1 - 10\% (Mishra, 2007). Although the incidence of ARF has declined sharply in many developed countries, this disease is still a major problem in developing countries (Jaine, 2011). The prevalence of streptococcal infections in developing countries is linked to factors including the socio-economic situation, inadequate health services, untreated or slowly handled throat infections, sometimes a dense environment, industrialization, and urbanization (Minodier, 2014).

In Asia, RHD is estimated to affect 10.8-15.9 million patients with a mortality rate of $356,000-524,000$ each year. In 2016, Rodriguez found and reported limited data about the incidence of RHD in Indonesia (Rodriguez, 2015). Julius' study in 2016 revealed that the prevalence of RHD in Indonesia was $0.3-0.8 \%$ with an age range of 5-15 years (Julius, 2016) Limitations of the data showed the difficulties in handling the problem quickly and accurately. Carapetis reported that treatment and prevention of a post-infection are very crucial, as this type of disease has a high incidence of mortality (Carapetis, 2007).

In Aceh - Indonesia, the incidence of ARF and RHD has not been properly recorded as it is difficult to collect the data on the diseases. We had collected data from sixty-three subjects with ARF and RHD during the period of 2015-2017. We studied the factors that trigger ARF and RHD infections, particularly the relationship between the distribution of the disease and clinical diagnosis with residence and interaction time as the substance for analysis in this study. Therefore, the aim of this study was to obtain diagnostic data as well as information for the treatment of streptococcal infections with the assumption of ARF and RHD.

\section{Methods}

\subsection{Material}

The data of sixty-three subjects with ARF and RHD infections were collected from May 2015 to May 2017. The subjects were children aged 4 - 18 years who were sent by colleague doctors from district hospitals all over Aceh who were referred for treatment at Zainal Abidin Hospital, Banda Aceh - Indonesia with suspicions of ARF and RHD. The subjects were interviewed to find out the information about the infection. A diagnosis of ARF and RHD used the anti-Streptolysin titer O (ASTO), as well as an examination of the rate of blood sedimentation and CRP (C-reactive protein), together with an X-ray examination, electrocardiograph (ECG), and echocardiography.

\section{a. Participation Informed Consent Statement}

The study was approved by Ethical Clearance Committee of the Faculty of Medicine, Universitas Syiah Kuala, Banda Aceh, Indonesia No: 309/KE/ FK/2015.

\subsection{Methods}

\section{a. Subject Interviews}

Subjects with suspected ARF and RHD were interviewed about infection and then their responses were compared with the subjects' medical records related to their history of illness, including fever, joint pain and swelling, palpitations, tightness, and walking ability. Moreover, the subjects were examined for nutritional status and information about the interactions of the environment and residence status, including home profiles such as information on floor, ventilation, and the number of residents living in the house. This was accomplished through the use of the principle of Major and Minor by Jones criteria, with the PR-Interval $<0.16$ (normal) and $>0.16$ being abnormal electrocardiography (Gewitz, 2015). 


\section{b. Complete Blood Count Assay}

Complete blood tests were carried out on 63 subjects' blood samples to strengthen the diagnosis of ARF and RHD. Complete blood tests included evaluate hemoglobin, hematocrit, blood sedimentation rate, and leukocytes. Furthermore, chest X-rays, electrocardiograph examinations (Fukuda, Japan) were carried out on the subjects to establish that they had heart valve problems. Finally, echocardiography was analyzed (General electric, Japan) using a Kappa value of 0.6, which is considered a good indicator.

\section{c. Anti Streptolysin Titer O Analysis}

The anti-streptolysin titer O (ASTO) examination was performed using a semiquantitative laboratory approach to determine the anti-streptolysin titer O (ASTO) levels. ASTO is a type of antibody that is most often used as an indicator of streptococcal infection in cases of ARF or RHD. The working principle of the ASTO examination involves formation of agglutination as a result of a reaction between serum containing ASTO antibodies and a latex suspension containing particles coated with purified streptolysin O. The identification of subjects with Streptococcal infection began with taking 63 subjects' blood and serum samples, further diluting the serum with $0.9 \% \mathrm{NaCl}$ using a micropipette from dilutions $1 / 2,1 / 4,1 / 8$, $1 / 16,1 / 32,1 / 64$ (1:2), etc. Furthermore, an amount of 50 ul of serum from each dilution was placed on the object glass, and $50 \mathrm{ul}$ of latex reagent was added and widened using a stick (stirrer) until the dark circle on the object glass became full. Next, It was shaken and the agglutination in front of the light was observed for 2 minutes by turning on the stopwatch. The qualitative assessment of ASTO (+) is when agglutination occurs (levels of $\geq 200 \mathrm{IU} / \mathrm{ml}$ ) or ASTO (-) if there is no agglutination. Meanwhile, the semi-quantitative assessment was done by examining the anti-streptolysin antibody titers with the highest dilution, and it showed agglutination (Kotby, 2012).

\section{d. C-reactive Protein Assay}

Blood tests were carried out on subjects with a suspected infection that showed inflammation by using the C-reactive protein (CRP) assay, specifically to detect rheumatoid disease. Blood samples of subjects were examined using the hs-CRP (high sensitivity C reactive protein) assay that was used as a marker. Standard reading of CRP values $<1.0 \mathrm{mg} / \mathrm{dl}$ indicated a (low risk), 1-3 mg / dl a (moderate risk), and > $3.0 \mathrm{mg} / \mathrm{dl}$ a (high risk) (Zhang, 2015).

\section{e. Statistical Analysis}

The data obtained were analyzed using SPSS 18, and the correlations between the variables analyzed were. Strong $(r=1, p<0.05)$.

\section{Results and Discussion}

\subsection{Result}

We conducted this research for two years (2015 - 2017) at Zainoel Abidin Public Hospital (RSUZA), Banda Aceh, Aceh - Indonesia. RSUZA is the referral hospital for all districts in the province of Aceh and became the center for report analysis of ARF and RHD infections. The total infections of ARF and RHD included 63 samples (males 50.8\%; 32 samples of females (49.2\%:31 samples). The distribution of the subject population in research was (\%: subjects). Male groups suspected as having ARF: severe (34\%:11), medium (63\%:20), and mild (1\%:1). For RHD infections: severe (41\%:13), medium (6\%:2), mild (13\%:4), and normal (41\%:13). For the female groups with suspected ARF: severe (16\%:5), medium (77\%:24), and mild (6\%:2). For RHD infections: severe (35\%:11), medium (10\%:3), mild (23\%:7), and normal (32\%:10). In figure 1, showed the distribution of ARF and RHD 
infections in Aceh-Indonesia. In regard with the distribution of ARF and RHD infections in Aceh-Indonesia, we found 63 samples of populations that suffered from streptococcal infections, with RHD cases were larger in number than ARF ( $\mathrm{p}<0.05)$. Also, both RHD and ARF were correlated $(\mathrm{r}=0.88)$.

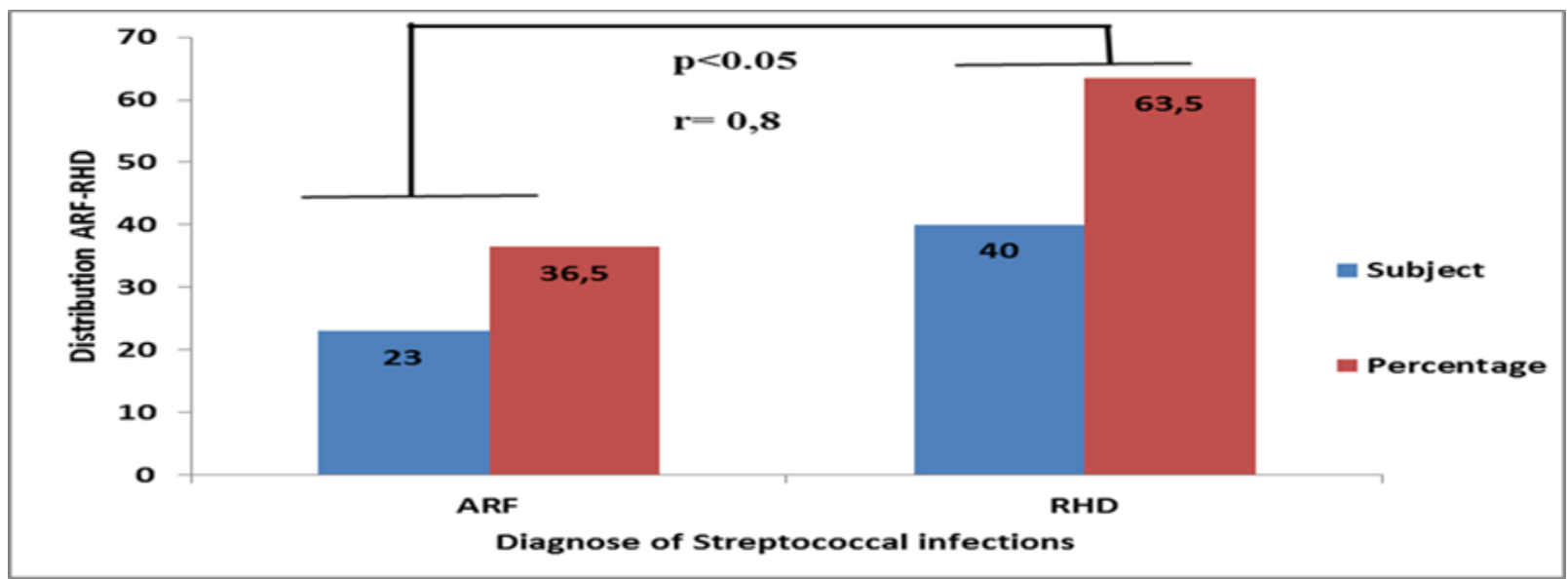

Figure 1. Diagnoses of Streptococcal infection (ARF and RHD) in Aceh, Indonesia (20152017)

Table 1 shows the characteristics of research subjects of ARF and RHD infection using ASTO assay and found $800-1200$ result of $50.8 \%$ and living in not healthy homes result of $79.4 \%$. No subject with poor nutritional status, but over-nutrition were higher result of $55.6 \%$.

Table 1. Characteristics of Research Subjects

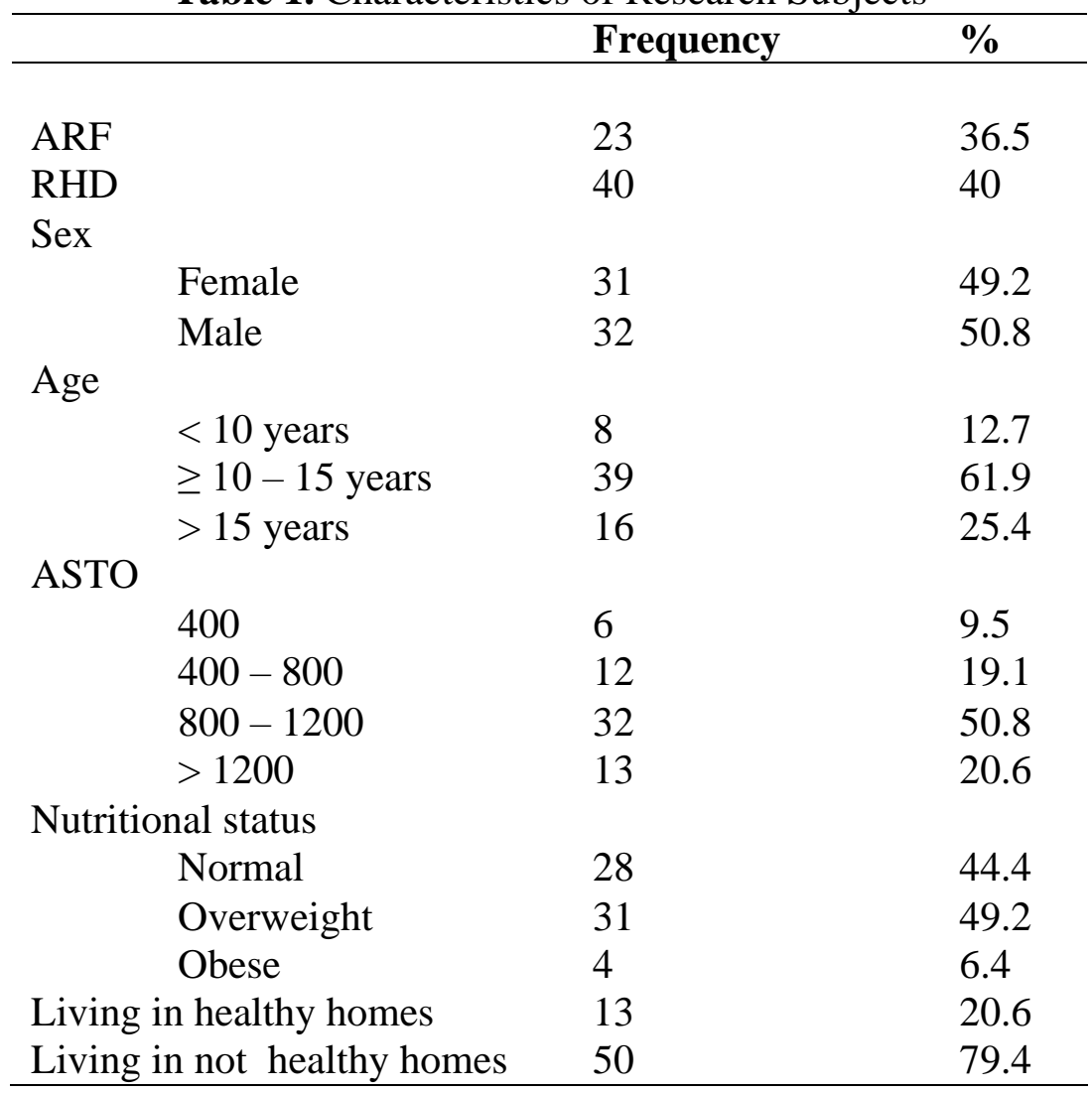

The scale of infection, including severe, medium, mild, and normal in ARF and RHD 
infections were not significant ( $p>0.05$ ), with a correlation coefficient of $r=0.06$. It has been correlated with the results of Table I, where these infections had no correlation with age and $\operatorname{sex}(\mathrm{p}>0.05)$.

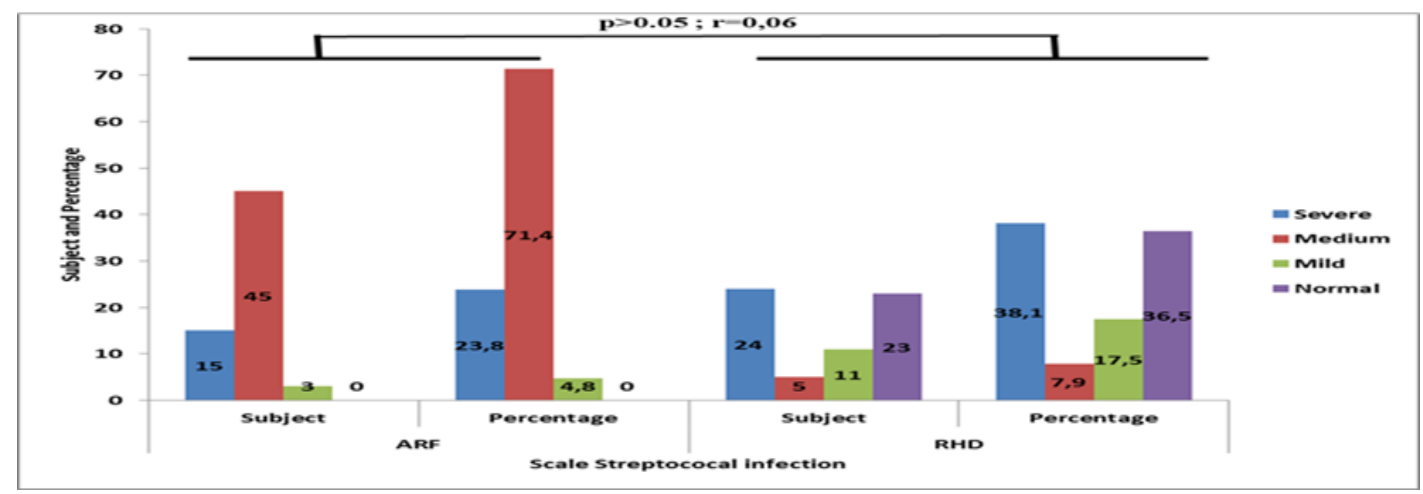

Figure 2. Scale of Streptococcal infection (ARF and RHD)

Table 2 shows the factors of residence and environmental interaction affecting the incidence of ARF and RHD.

Table 2. Correlations of Variables with Severity of Illness

\begin{tabular}{ll}
\hline Variable & Spearman's Correlation \\
\hline Age & $0.468(\mathrm{P}=0.000)$ \\
$\begin{array}{l}\text { The duration of interaction in the school } \\
\text { environment }\end{array}$ & $0.281(\mathrm{P}=0.026)$ \\
Quality of housing & $0.143(\mathrm{P}=0.262)$ \\
\hline
\end{tabular}

Based on Spearman's correlation analysis (Table 2), it was shown that for residence, The ARF was significant ( $\mathrm{p}<0.05)$, with a correlation coefficient of $(\mathrm{r}=0.262)$. Meanwhile, RHD was not significant ( $p>0.05)$. For the Interaction of time and environment, the RHD infection was significant $(p<0.05)$, but the ARF was not significant $(p>0.05)$. Generally, the environmental factors in ARF and RHD infections for residence and interaction of time and environment were significant $(\mathrm{p}<0.05)$ for the spread of ARF and RHD infections.

Table 3. Damage Valve based on Echocardiography examination.

\begin{tabular}{lll}
\hline Damage Valve & Frequency & $\%$ \\
\hline Mitral , aorta and tricuspid regurgitation & 15 & 37.5 \\
$\begin{array}{l}\text { Mitral and aorta or } \\
\text { Mitral and tricuspid regurgitation }\end{array}$ & 20 & 50 \\
Mitral regurgitation or mitral stenosis & 5 & 12.5 \\
\hline
\end{tabular}

\subsection{Discussion}

$\mathrm{ARF}$ and RHD were classified as non-suppurative pharyngeal infections caused by group A $\beta$-hemolytic Streptococcus. Generally, cases that occurred in developing countries when compared to those in developed countries had disproportionate numbers between the incidence of RHD and ARF in each individual sufferer (Roberts, 2017). The World Heart Federation states that the echocardiographic criteria for the RHD diagnosis are included in infections for a 
limited category of "borderline." The children with borderline RHD status may have an increased risk of ARF with progression of valvular lesions, which can be a determinant of an RHD infection.

The results showed that there were no significant differences between the incidence of ARF and RHD based on sex in the age group of 5 - 15 years, although it was reported to be significant in other studies. Global research showed significant differences between ARF and RHD based on this age factor $(\mathrm{p}<0.05)$. Streptococcal infection at an early age is very common because this type of bacteria can reduce the human immunity at that age period, which may be caused by poor sanitation, thus affecting the circulation system. This could trigger the spread of streptococcus bacteria. In RHD cases, a number of immunity cells are involved, such as T lymphocytes as the main effector of the cross-reaction between streptococcus and human cells, such as the response to cytokines. Streptococcal infection also to develop neuropsychiatric symptoms or syndrome of pediatric autoimmune neuropsychiatric.

Data showed that the distribution of streptococcal infections (ARF and RHD) was in line with the diagnosis performed ( $\mathrm{p}<0.05$ ), meaning that to strengthen the choice of diagnostic methods of the evaluation material, it had to be in line with the clinical analysis. Blood tests, $\mathrm{x}-$ ray examinations, and detection with $\mathrm{C}$-reactive protein and anti-streptolysin $\mathrm{O}$ are among several analyses suggested by the Guidelines for Evaluation and Management of Chronic Heart Failure in the Adult. Table I shows that the Friedman test was significant $(\mathrm{p}<0.05)$ among ARF and RHD patients, according to clinical analysis variables to diagnose ARF and RHD infections and with the chi-square analysis showing that these variables had different meanings when triggering ARF and RHD infections. In the same table, the Chi-square analysis indicated that the sex variables (male and female) were non-significant ( $p>0.05$ ). It was explained that sex had not influenced the distribution of ARF and RHD infections. The diagnose status reported 63 subjects analyzed by Antistreptolysin O ARF and RHD were significant $(\mathrm{p}<0.05)$. Besides, the weight status influences in ARF and RHD were significant $(p<0.05)$. Generally, based on the Friedman test, seven variables were significant $(p<0.05)$.

Table 1 also shows that blood test is an important part of the diagnosis for both infections. Among its functions is to detect a number of inflammatory components and immune responses that cause RHD. These generally affect the heart valves, which can cause the heart not to pump the blood properly, a condition called RHD. Furthermore, Table 1 also shows the results of the RHD electrocardiograph examination, which looked at the cardiac profile based on the clinical analysis. The results were $61.9 \%$ ECG-left ventricle hypertrophy, 61.9\% ECG-left atrial enlargement, ECG-right ventricle hypertrophy 34.9\%, ECG-right ventricle enlargement (34.9\%), and 69.8\% ECG-P interval. John's criteria were not normal. Echocardiography can be used to diagnose the abnormal function of the heart chamber. ${ }^{25}$ The ARF diagnosis showed subjects with high severity, RHD subjects suffered from changes in the left ventricle for both hypertrophy and enlargement aspects. John's criteria index showed positive subjects had ARF and RHD infections. Meanwhile, general RHD included advanced infections, including mitral and aortic valve stenosis or insufficiency, pericarditis, arrhythmias, and heart failure.

Miller reported that the ECG results showed a left atrial abnormality could be considered as an early sign of hypertensive heart disease. The secondary mitral valve prolapse may have resulted from damage to valvular structures during acute myocardial infection, rheumatic heart disease, or hypertrophic cardiomyopathy (which occurs when the muscle mass of the left ventricle of the heart is larger than normal). The mitral valve is most commonly and severely affected (65 - 70\% of patients), followed by the aortic valve (25\%), and the tricuspid valve $(10 \%)$. Fusion of the valve is needed 2 - 10 years after an episode of acute rheumatic fever, and recurrent episodes may cause progressive damage to the valves. Fusion occurs at the level of the valve commissures, cusps, chorda attachments, or any combination of these. Variables that correlate with the severity of valve disease included the number of previous attacks of 
rheumatic fever and the length of time between the onset of the disease and the start of therapy.

Table 2 shows the statistical non-parametric data which indicated that the ARF infection had a significant relationship with residence $(\mathrm{p}<0.05)$. Subjects with an unhealthy residence were 50 of 62 subjects $(79.4 \%)$, while there were 13 subjects $(20.6 \%)$ living in healthy residence. This means that an unhealthy residence may trigger an outbreak of this infection. In this study, time interaction with the environment became a factor that worsened the spread of RHD ( $\mathrm{p}<0.05)$, with a correlation coefficient $(\mathrm{r}=0.302)$. Even though only 23 subjects $(36.5 \%)$ were in the bad category, the environment had a great influence on the spread of this infection. Consistent with these data, the two factors that trigger ARF and RHD infections had different effects from one another when they cause the streptococcal infection. It is also in line with the data found by Tang about aerosol infection. Beg in Pakistan showed that the prevalence of ARF and RH was influenced by several risk factors, including environmental health conditions, poverty, and illiteracy.

Environmental factors affect the prevalence of ARF by increasing exposure to $\mathrm{S}$. pyogenes infections. A major environmental factor that increases the likelihood of ARF is household crowding, which facilitates the spread of S. pyogenes infections (Walker, 2014). In addition, it has been shown that ARF and RHD are more prevalent in rural and remote areas as well as in urban slums, but this likely reflects other risk factors, such as greater household crowding due to low socioeconomic status or limited access to medical resources. There is also a potential link between insufficient nutrition in childhood and susceptibility to ARF, however, it is unclear whether this occurs because insufficient nutrition can increase susceptibility to developing aggressive autoimmune responses to the S. pyogenes infection, or because poor nutrition is connected to household overcrowding and other factors associated with poverty that increases susceptibility to S. pyogenes infections (Steer, 2002).

The population consisted of males $(32: 50.8 \%)$ and females $(31: 49.2 \%)$, while the streptococcal infection of RHD was $63.5 \%$, higher than ARF (36.5\%). The clinical diagnoses of RHD and ARF were significant $(\mathrm{p}<0.05)$. Also, the residence and the interaction of the environment had influenced the RHD and AFR.

\section{Conclusion}

Our study concluded that, age of subject shows a moderate positive correlation with the incidence of ARF and RHD, while the length of time at school interaction was weakly correlated with the incidence of ARF and RHD. The results also showed that the quality of housing did not correlated with severity of ARF and RHD patient.

Many subjects have more than two valve demage. Mitral valve demage occur in twothirds subjects. The severity of illness very depend on number of valve's damage

\section{Acknowledgments}

The authors would like to thank the Division of Pediatric Cardiology, Sub-Division of Children's Health Sciences, Faculty of Medicine, Syiah Kuala University, Zainoel Abidin Hospital, Banda Aceh, Indonesia.

\section{References}

Beg, A, Younas M. Rheumatic heart disease (RHD); Socio-economic and environment risk factors for acut rheumatic fever (ARF) and rheumatic heart disease (RHD) patients in Pakistan. Professional Med J 2016;23:324-327. 
Budapest International Research in Exact Sciences (BirEx) Journal Volume 2, No 2, April 2020, Page: 248-256 e-ISSN: 2655-7827 (Online), p-ISSN: 2655-7835(Print) www.bircu-journal.com/index.php/birex emails: birex.journal@gmail.com

Boon NA, Bloomfield P. The medical management of valvar heart disease. Heart 2002;87:395400.

Carapetis JR, Beaton A, Cunningham MW, et al. Acute rheumatic fever and rheumatic heart disease. Nat Rev Dis Primers 2016;2:15084.

Carapetis JR. Rheumatic heart disease in developing countries. N Engl J Med 2007;357:439441

Cengel-Kültür SE, Cöp E, Kara A, Cengiz AB, Uludağ AK, Unal F. The relationship between group A beta hemolytic streptococcal infection and psychiatric symptoms: a pilot study. Turk J Pediatr. 2009;51:317-324.

Coffey PM, Ralph AP, Krause VL. The role of social determinants of health in the risk and prevention of group A streptococcal infection, acute rheumatic fever and rheumatic heart disease: A systematic review. PLoS Negl Trop Dis 2018;12:e0006577.

Fieber C, Kovarik P. Responses of innate immune cells to group A Streptococcus. Front Cell Infect Microbiol 2014;4:140.

Gewitz MH, Baltimore RS, Tani LY, et al. Revision of the Jones Criteria for the diagnosis of acute rheumatic fever in the era of Doppler echocardiography: a scientific statement from the American Heart Association. Circulation 2015;131:1806-1818.

$\mathrm{Hu} \mathrm{W}$, Ye Y, Yin Y, et al. Association of matrix metalloprotease 1, 3, and 12 polymorphisms with rheumatic heart disease in a Chinese Han population. BMC Med Genet 2018;19:27.

Jaine R, Baker M, Venugopal K. Acute rheumatic fever associated with household crowding in a developed country. Pediatr Infect Dis J 2011;30: 315-319.

Julius WD. Rheumatic heart disease. J Medula 2016;4:138-144.

Kamel H, Bartz TM, Longstreth WT, et al. Association between left atrial abnormality on ECG and vascular brain injury on MRI in the Cardiovascular Health Study. Stroke 2015;46:711-716.

Kotby AA, Habeeb NM, Ezz El Elarab S. Antistreptolysin O titer in health and disease: levels and significance. Pediatr Rep 2012;4:e8.

Maganti K, Rigolin VH, Sarano ME, Bonow RO. Valvular heart disease: diagnosis and management. Mayo Clin Proc 2010;85:483-500.

Minodier P, Laporte R, Miramont S. Epidemiology of Streptococcus pyogenes infections in developing countries. Arch Pediatr 2014;21(Suppl 2):S69-S72

Mishra T. Acute rheumatic fever and rheumatic heart disease: current scenario. J Indian Acad Clin Med 2007;8: 324-330.

Nkomo VT. Epidemiology and prevention of valvular heart diseases and infective endocarditis in Africa. Heart 2007;93:1510-1519.

Oliver SJ, Cush J, Ward JE. Community-Based Prescribing for Impetigo in Remote Australia: An Opportunity for Antimicrobial Stewardship. Front Public Health 2017;5:158.

Ozer S, Hallioğlu O, Ozkutlu S, Celiker A, Alehan D, Karagöz T. Childhood acute rheumatic fever in Ankara, Turkey. Turk J Pediatr. 2005 Apr-Jun;47:120-124.

Rothenbühler M, O'Sullivan C, Stortecky S, et al. Active surveillance for rheumatic heart disease in endemic regions: a systematic review and meta-analysis of prevalence among children and adolescents. Lancet Glob Health 2014;2:e717-e726.

Rodriguez-Fernandez R, Amiya R, Widdodow W, Carapetis J. Rheumatic heart disease among adults in a mining community of Papua, Indonesia: findings from an occupational cohort. Heart Asia 2015;7:1-5.

Roberts K, Cannon J, Atkinson D, Brown A, Maguire G, Remenyi B. Echocardiographic Screening for Rheumatic Heart Disease in Indigenous Australian Children: A CostUtility Analysis. J Am Heart Assoc. 2017;6:e004515.

Reményi B, Wilson N, Steer A, Ferreira B, Kado J, Kumar K. World Heart Federation criteria for echocardiographic diagnosis of rheumatic heart disease--an evidence-based guideline. Nat rev. Cardiol 2012;9297-9309. 
Seckeler MD, Hoke TR. The worldwide epidemiology of acute rheumatic fever and rheumatic heart disease. Clin Epidemiol 2011;3:67-84.

Steger CM. Rheumatic heart disease. BMJ Case Rep. 2015;2015:bcr2015211943.

Shulman ST, Tanz RR. Group A streptococcal pharyngitis and immune-mediated complications: from diagnosis to management. Expert Rev Anti Infect Ther 2010;8:137150.

Steer AC, Carapetis JR, Nolan TM, Shann F. Systematic review of rheumatic heart disease prevalence in children in developing countries: the role of environmental factors. $\mathrm{J}$ Paediatr Child H 2002;38:229-234.

Süleymanoğlu S, Okutan V, Yozgat Y, Lenk MK. Determination of normal echocardiographic values for right ventricular volume in children with two-dimensional transthoracic echocardiography. Turk J Pediatr. 2007;49:141-147.

Tandon R, Sharma M, Chandrashekhar Y, Kotb M, Yacoub MH, Narula J. Revisiting the pathogenesis of rheumatic fever and carditis. Nat Rev Cardiol 2013;10(3):171-177.

Tang JW, Li Y, Eames I, Chan PK, Ridgway GL. Factors involved in the aerosol transmission of infection and control of ventilation in healthcare premises. J Hosp Infec 2006;64:100114.

Watkins DA, Johnson CO, Colquhoun SM, et al. Global, regional, and national burden of rheumatic heart disease, 1990-2015. N Eng J Med 2017;377:713-722.

Walker MJ, Barnett TC, McArthur JD, et al. Disease manifestations and pathogenic mechanisms of Group A Streptococcus. Clin Microbiol Rev 2014;27:264-301.

Yancy CW, Jessup M, Bozkurt B, et al. ACCF/AHA Guideline for the Management of Heart Failure. J Am Coll Cardiol. 2013;62:e147-e239.

Zhang P, Bao Y, Draz MS, Lu H, Liu C, Han H. Rapid and quantitative detection of C-reactive protein based on quantum dots and immunofiltration assay. Int $\mathrm{J}$ Nanomedicine. 2015;10:6161-6173. 